\title{
Significant reduction of radiation exposure using a protection cabin for electrophysiological procedures
}

\author{
Christiana Schernthaner*, Franz Danmayr ${ }^{\dagger}$ and Bernhard Strohmer ${ }^{\dagger}$ \\ *Correspondence: c.schernthaner@salk.at \\ 'These authors contributed equally to this work. \\ Paracelsus Private Medical University, Salzburger Landeskliniken, Department of Cardiology, Muellner Hauptstrasse 48, A-5020 \\ Salzburg, Austria.
}

\begin{abstract}
Background: Fluoroscopy is the main visualization technique for EP procedures. A radiation protection cabin (RPC) shielded with $2 \mathrm{~mm}$ lead-equivalent walls was tested as an alternative protection tool (Cathpax ${ }^{\circledR}$, Lemer Pax).

Methods: To assess the scattered radiation to the operator inside the RPC an electronic personal dosimeter (EPD; Mk2, Thermo Electron) was placed at the neck level of the operator. A second EPD was located outside the RPC at $150 \mathrm{~cm}$ height from the floor, to record the presumable head radiation dose.

Results: Radiation doses were measured in a total of 138 consecutive patients (age $54 \pm 16$ yrs, BMI $28 \pm 5 \mathrm{~kg} / \mathrm{m}^{2}(18-45), 64 \%$ male) undergoing a variety of ablation procedures ( $\mathrm{SVT}=75, \mathrm{AFL}=32, \mathrm{AF}=17, \mathrm{VT}=14)$. Median fluoroscopy time was $39 \mathrm{~min}$ (7-140), the cumulative dose-area product (DAP) $4702 \mathrm{cGy} \cdot \mathrm{cm}^{2}$ (493-65620). Doses outside the RPC showed a median of $135 \mu \mathrm{Sv}$ (1-4881). Doses inside the RPC were detected only at sensitivity threshold or background levels (mean $0.2 \mathrm{SD} 0.7 \mu \mathrm{Sv}$, median 0.0 , range $0-4$ ). The dose reduction to the operator was highest for AF ablations (354 vs $0.5 \mu \mathrm{Sv}$, respectively; $\mathrm{p}<0.001$ ). The total accumulated dose outside the RPC was $37883 \mu \mathrm{Sv}$ for all 138 procedures, whereas for the protected operator inside only $30 \mu \mathrm{Sv}$.

Conclusions: There were highly concordant low dose values measured for the operator inside the RPC in comparison to high doses outside the RPC. The use of a RPC represents a major benefit over a lead apron and contributes to a significant dose reduction as low as reasonably achievable (ALARA principle).
\end{abstract}

Keywords: Radiation exposure, electrophysiological study, dose reduction, fluoroscopy

\section{Introduction}

Despite introduction of three-dimensional mapping and improved ablation technology, fluoroscopy will remain the main visualization technique for electrophysiological (EP) procedures. Furthermore, the complexity and the volume of invasive EP studies have substantially increased over the last decades. Especially ablation of atrial fibrillation (AF) is a complex and prolonged procedure and associated with high radiation doses due to prolonged fluoroscopy times of more than 120 minutes depending on anatomic variations and operator experience $[\mathbf{1}, \mathbf{2}]$. High cumulative radiation exposure of the operator may result in potential stochastic and deterministic sequels [3-5].Traditional radiation protection with lead aprons, goggles, and a thyroid shield leaves unprotected body parts such as arms, hands and head. Moreover, lead aprons are heavy and uncomfortable for the operator during prolonged procedures. In this study a radiation protection cabin (RPC) (Cathpax ${ }^{\circledR}$, Lemer Pax, Carquefou, France) shielded with $2 \mathrm{~mm}$ lead-equivalent walls was tested as an alternative protection tool (Figure 1). The RPC is mobile, adjustable in height, and is prepared with specifically designed drapes to provide sterile patient access. The main objective was the comparison of radiation doses inside the RPC versus outside the RPC for different ablation procedures.

\section{Methods}

The X-ray system used for EP procedures was a biplane (83\% of cases) or monoplane Philips Allura Xper FD10 system (Philips Healthcare; DA Best, The Netherlands). Pulsed low frame fluoroscopy ( 7.5 frames per second) and entrance dose limitation were used for air kerma reduction. The tubes of both systems have integrated dose-area product (DAP) meters indicating the cumulative DAP in $\mathrm{cGy} . \mathrm{cm}^{2}$ of each interventional procedure. DAP is a surrogate marker for the total amount of radiation energy delivered to the patient, hence serving as a relative indication of the scatter-dose to the operator.

To assess the scattered radiation to the operator inside the RPC an electronic personal dosimeter (EPD Mk2, Thermo Fisher Scientific, Waltham, MA) was placed at the back of the neck of the operator (Figure 1). A second EPD was located outside the RPC on the left-sided lateral wall of the cabin, at $150 \mathrm{~cm}$ height from the floor (Figure 2), to record the presumable head radiation dose. Dose display and storage of the EPD Mk2 ranges from $0 \mu \mathrm{Sv}$ to $>16 \mathrm{~Sv}$ (auto ranging) at a resolution of $1 \mu \mathrm{Sv}$ up to $10 \mathrm{mSv}$.

\section{Statistical analysis}

Data for continuous variables were expressed as mean \pm standard deviation (SD) or median if appropriate. Data were 


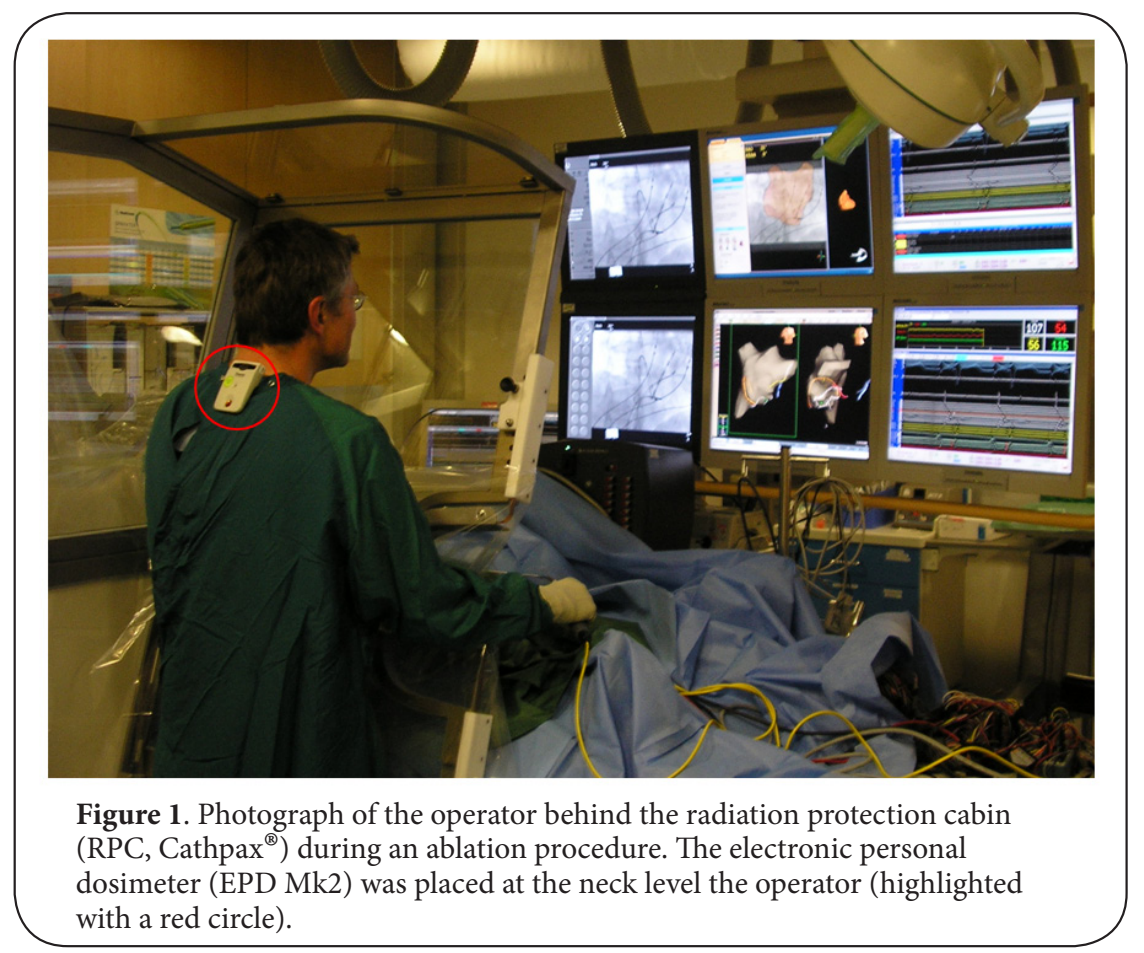

Table 1. Patient and procedure characteristics.

\begin{tabular}{ll}
\hline Characteristics & $\begin{array}{l}\text { Number of Patients } \\
\text { (Total N=138) }\end{array}$ \\
\hline Men / Women & $88 / 50$ \\
Mean age & $54 \pm 16$ y (16-81) \\
Body mass index & $28 \pm 5 \mathrm{~kg} / \mathrm{m}^{2}(18-45)$ \\
Number of Total Ablation Procedures & 138 \\
Supraventricular Tachycardia & 75 \\
AVNRT & 45 \\
AP & 15 \\
AT & 8 \\
AVN ablation & 3 \\
PJRT & 1 \\
AVNRT and AT & 1 \\
AVNRT and RVOT tachycardia & 1 \\
AP and AFL and AVNRT & 1 \\
\hline
\end{tabular}

compared using a two-sided Student's $t$-test. A p-value $<0.05$ was considered statistically significant. All statistical analyses were performed using Minitab 15 statistical software. Radiation doses are expressed in standard international (SI) units.

\section{Results}

All ablation procedures were performed with the RPC in use without compromising catheter manipulations of the operator. To gain access to both femoral veins and the right jugular vein all vessel punctures and the introduction of sheaths were performed before placement of the cabin.

The study compromised a total of 138 consecutive ablation procedures (supraventricular tachycardia (SVT) $=75$, atrial flutter $(A F L)=32$, atrial fibrillation $(A F)=17$, ventricular tachycardia $(\mathrm{VT})=14)$. Mean age of the patients was $54 \pm 16$ years, body mass index $28 \pm 5 \mathrm{~kg} / \mathrm{m}^{2}$ (range 18-45), $64 \%$ men (Table 1). Median fluoroscopy time was $39 \mathrm{~min}$ (range 7-140). The externally applied radiation energy per minute fluoroscopy, as measured by the cumulative DAP was 4702 cGy.cm² (range 493-65620). Doses outside the RPC showed a median of $135 \mu \mathrm{Sv}$ (range 1-4881). In 9/138 ablations (6.5\%) doses were $>1000 \mu \mathrm{Sv} /$ procedure, indicating a high exposure to the head (Figure 3 ). Doses inside the RPC were detected only at sensitivity threshold or background levels (mean 0.2SD0.7 $\mathrm{SSv}$, median 0.0, range 0-4) (Figure 4). The dose reduction to the operator was highest for $\mathrm{AF}$ ablations when comparing values outside versus inside the cabin (354 versus $0.5 \mu \mathrm{Sv}$, respectively; $\mathrm{p}<0.001$ ). The total accumulated dose outside the RPC was $37883 \mu$ Sv for all 138 procedures, whereas for the protected operator inside only $30 \mu \mathrm{Sv}$.

\section{Discussion}

The present study demonstrates that the use of the RPC significantly reduces the radiation dose to the invasive electrophysiologist as low as reasonably achievable (ALARA principle). The dose values measured for the operator inside the cabin were concordant low among all procedures. Our data are in line with the findings by Dragusin et al., [6] who demonstrated the usefulness of the RPC cabin compared to traditional radiation protection. In contrast to the cited study, we used a biplane X-ray system for the majority of ablation cases (>80\%), whereas Dragusin et al., reported the use of 


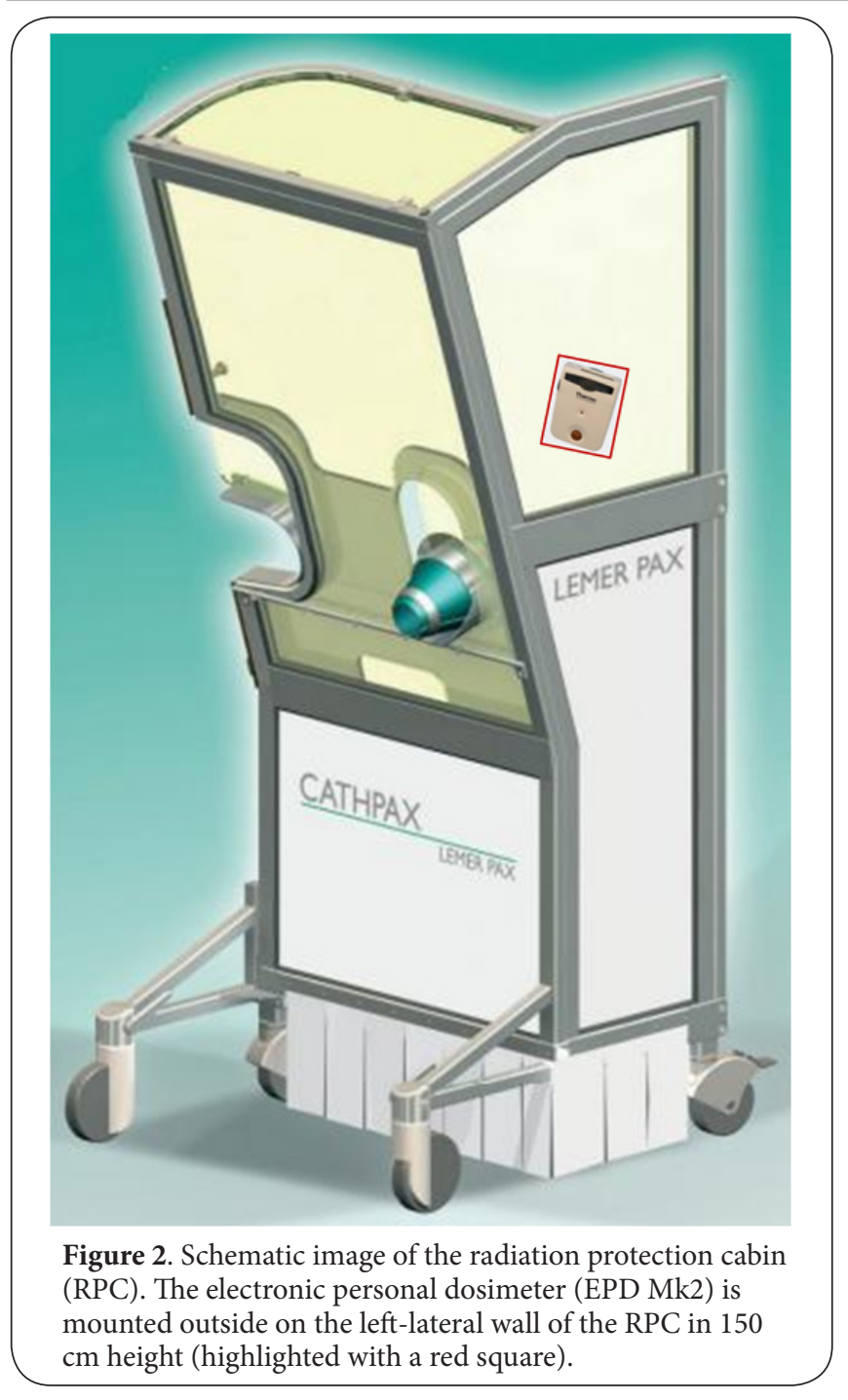

a monoplane system in $70 \%$ of the procedures. As a major difference the French and Belgian investigators compared electrophysiological procedures with protection provided by classical means (lead apron) versus the RPC. Doses were measured with either thermoluminiscent or electronic dosimeters at multiple sites in protected and unprotected areas, whereas in our study all procedures were performed with the operator behind the RPC using only two EPDs, one inside the other outside the RPC. This setting was chosen in light of the results of the previously published study that found significant differences between conventional protection and the RPC particularly for radiation exposure to the head and neck of the operator. However, the different fluoroscopic systems, types of ablation and measurement techniques in both studies preclude a direct comparison of doses. Nevertheless, our findings confirm the significant reduction of radiation dose particularly to unprotected areas of the body that can be achieved using the RPC in a variety of more or less complex electrophysiological procedures.

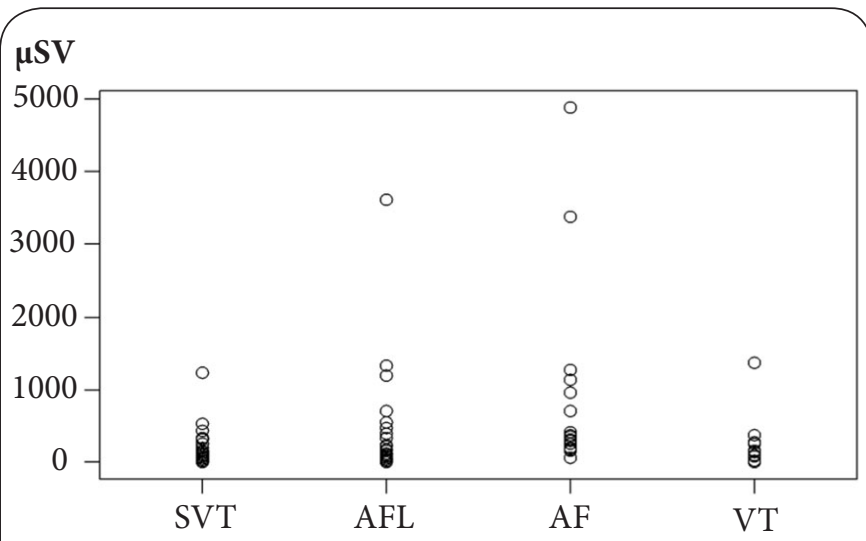

Figure 3. Graph showing dotplots of radiation doses $(\mu \mathrm{Sv})$ measured during radiofrequency ablation of various arrhythmias. SVT = supraventricular tachycardia, AFL = atrial flutter, $\mathrm{AF}=$ atrial fibrillation, $\mathrm{VT}=$ ventricular tachycardia.

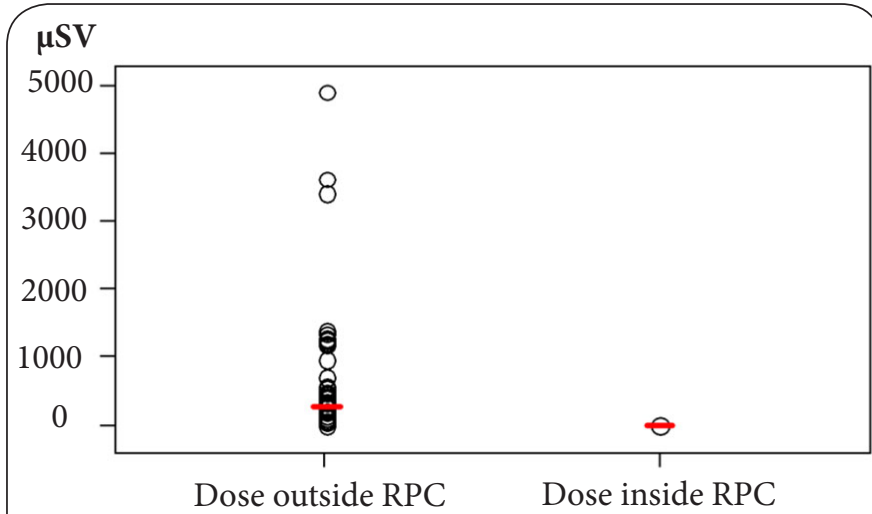

Figure 4. Graph showing dotplots of the specific radiation dose per procedure $(\mu \mathrm{Sv})$ as measured outside versus inside the RPC. The mean values are indicated as red lines.

Renaud [7] reported an annual dose exposure to the head of invasive cardiologist in the range of 20-30 mSv per year. Furthermore there are data indicating an increased risk of brain tumours in medical radiation workers because of absence of head protection [4]. In the present study the electronic dosimeter outside the cabin was placed in a way to record the presumable head radiation dose. The doses measured outside the cabin indicate that EP operators are exposed to relatively high radiation levels without shielding, particularly to the regions of the head and neck. Dose values inside the cabin were negligible low. Therefore, the dose reduction with the RPC, covering head and arms, certainly represents a benefit over the use of conventional radioprotection, such as lead aprons, a lead glass screen or lead eye glasses [8].

Over the last decade the number of AF ablations has dramatically increased and the trend is likely to continue in the future. AF ablation procedures are complex, prolonged and associated with larger radiation doses $[1,2]$. Lickfett and coworkers reported a fourfold increase in fluoroscopic 
Schernthaner et al. Medical Imaging and Radiology 2013,

screening time for AF ablations compared to AFL ablations and an eightfold increase compared to AVNRT ablation procedures [2]. The present study confirmed this finding and documented high radiation doses, particularly for complex AF ablations. Consequently, the dose reduction to the operator was highest for left atrial ablation procedures.

The work behind the RPC is much more comfortable compared to wearing a heavy lead apron, especially during prolonged procedures. Long-term orthopaedic problems are increasing in interventional cardiologists due to heavy lead aprons [9-11]. The use of the RPC on a routine basis might prevent such orthopaedic problems. However, the RPC has been designed mainly for electrophysiological procedures and until now there are no comparable protection systems available for coronary interventions or device implantations. In our experience, the RPC did not pose any hindrances to the operator with respect to catheter manipulation or even transseptal puncture for left atrial ablations. However, repositioning of the coronary sinus catheter from above was possible only form outside the RPC. Over the last years the regular use of the RPC has become routine in our EP laboratory independent of the type of the procedure. The consistent use of the RPC will ensure that individual dosimetry of high-volume operators will remain far below the upper recommended annual effective dose limit of $20 \mathrm{mSv}$ per year in our country.

\section{Conclusion}

The use of the RPC allowed the operators to perform a variety of catheter ablations without hindrance and negligible radiation. There were highly concordant low dose values measured inside the RPC over a clinically relevant wide spectrum of procedures. The doses measured outside the RPC confirm that electrophysiologists are exposed to relatively high dose levels, particularly during AF ablations. Use of a RPC represents a major benefit over a lead apron and contributes to a significant dose reduction as low as reasonably achievable (ALARA principle).

\section{Competing interests}

The authors declare that they have no competing interests.

Authors' contributions

\begin{tabular}{|l|l|l|l|}
\hline Authors' contributions & CS & FD & BS \\
\hline Research concept and design & -- & -- & $\checkmark$ \\
\hline Collection and/or assembly of data & $\checkmark$ & $\checkmark$ & $\checkmark$ \\
\hline Data analysis and interpretation & $\checkmark$ & -- & $\checkmark$ \\
\hline Writing the article & $\checkmark$ & -- & -- \\
\hline Critical revision of the article & -- & -- & $\checkmark$ \\
\hline Final approval of article & $\checkmark$ & -- & -- \\
\hline Statistical analysis & $\checkmark$ & -- & $\checkmark$ \\
\hline
\end{tabular}

Acknowledgement

The authors would like to thank Volker Schett for his technical assistance in this study.

\section{Publication history}

Editor: Maythem Saeed, University of California, San Francisco, USA. Received: 19-Sep-2013 Revised: 27-Sep-2013

Accepted: 03-Oct-2013 Published: 21-Oct-2013

\section{References}

1. Lickfett L, Mahesh M, Vasamreddy C, Bradley D, Jayam V, Eldadah Z, Dickfeld T, Kearney D, Dalal D, Luderitz B, Berger R and Calkins H. Radiation exposure during catheter ablation of atrial fibrillation. Circulation. 2004; 110:3003-10. | Article | PubMed

2. Macle L, Weerasooriya R, Jais P, Scavee C, Raybaud F, Choi KJ, Hocini $\mathrm{M}$, Clementy $\mathrm{J}$ and Haissaguerre $\mathrm{M}$. Radiation exposure during radiofrequency catheter ablation for atrial fibrillation. Pacing Clin Electrophysiol. 2003; 26:288-91. | Article | PubMed

3. Perisinakis K, Damilakis J, Theocharopoulos N, Manios E, Vardas P and Gourtsoyiannis N. Accurate assessment of patient effective radiation dose and associated detriment risk from radiofrequency catheter ablation procedures. Circulation. 2001; 104:58-62. I Article I PubMed

4. Yoshinaga S, Mabuchi K, Sigurdson AJ, Doody MM and Ron E. Cancer risks among radiologists and radiologic technologists: review of epidemiologic studies. Radiology. 2004; 233:313-21. I Article I PubMed

5. Calkins H, Niklason L, Sousa J, el-Atassi R, Langberg J and Morady F. Radiation exposure during radiofrequency catheter ablation of accessory atrioventricular connections. Circulation. 1991; 84:2376-82. | Article | PubMed

6. Dragusin O, Weerasooriya R, Jais P, Hocini M, Ector J, Takahashi Y, Haissaguerre $\mathrm{M}$, Bosmans $\mathrm{H}$ and Heidbuchel $\mathrm{H}$. Evaluation of a radiation protection cabin for invasive electrophysiological procedures. Eur Heart J. 2007; 28:183-9. | Article | PubMed

7. Renaud L. A 5-y follow-up of the radiation exposure to in-room personnel during cardiac catheterization. Health Phys. 1992; 62:10-5. | PubMed

8. Wittkampf FH, Wever EF, Vos K, Geleijns J, Schalij MJ, van der Tol J and Robles de Medina EO. Reduction of radiation exposure in the cardiac electrophysiology laboratory. Pacing Clin Electrophysiol. 2000; 23:163844. | PubMed

9. Ross AM, Segal J, Borenstein D, Jenkins E and Cho S. Prevalence of spinal disc disease among interventional cardiologists. Am J Cardiol. 1997; 79:68-70. | Article | PubMed

10. Goldstein JA, Balter S, Cowley M, Hodgson J and Klein LW. Occupational hazards of interventional cardiologists: prevalence of orthopedic health problems in contemporary practice. Catheter Cardiovasc Interv. 2004; 63:407-11. | Article | PubMed

11. Kuon E, Schmitt M and Dahm JB. Significant reduction of radiation exposure to operator and staff during cardiac interventions by analysis of radiation leakage and improved lead shielding. Am J Cardiol. 2002; 89:44-9. | Article | PubMed

\section{Citation:}

Schernthaner C, Danmayr F and Strohmer B. Significant reduction of radiation exposure using a protection cabin for electrophysiological procedures. Med Imaging Radiol. 2013; 1:1.

http://dx.doi.org/10.7243/2054-1945-1-1 